\title{
Future converging infrastructures
}

\author{
Assessing the consequences of increasing \\ sector coupling and integration
}

\begin{abstract}
Christian Büscher, Institute for Technology Assessment and Systems Analysis (ITAS), Karlsruhe Institute of Technology (KIT), Karlstr.11, 76133 Karlsruhe (christian.buescher@kit.edu) (1) https://orcid.org/0000-0002-8793-2438

Dirk Scheer, Institute for Technology Assessment and Systems Analysis (ITAS), Karlsruhe Institute of Technology (KIT) (dirk.scheer@kit.edu) (1) https://orcid.org/0000-0002-7472-8331
\end{abstract}

Lisa Nabitz, Institute for Technology Assessment and Systems Analysis (ITAS), Karlsruhe Institute of Technology (KIT) (lisa.nabitz@kit.edu)

The process of converging infrastructures - the integration and coupling of the energy, transport, heating and cooling sectors - challenges technological paradigms and economic structures as well as patterns of individual and collective action. Renewable energy sources (RES), physical and digital networks, and new market opportunities promise more efficient use of energy and reduced emissions. However, every technological solution creates new problems. Therefore, we propose to analyze possible developments by exposing socio-technical problems. This contribution analyses recent studies drawing on sector coupling and assesses the consequences of converging infrastructures.

\section{Zukünftige konvergierende Infrastrukturen}

Bewertung der Folgen einer zunehmenden Sektorkopplung

Der Prozess konvergierender Infrastrukturen - die Integration und Kopplung der Sektoren Energie, Transport und Wärme bzw. Kühlung fordert technologische Paradigmen und Wirtschaftsstrukturen heraus, ebenso wie Muster individuellen und kollektiven Handelns. Erneuerbare Energiequellen, physikalische und digitale Netze sowie neue Marktchancen versprechen einen effizienteren Umgang mit Ressourcen und eine Reduzierung von Emissionen. Jede neue Technologie erzeugt aber nicht nur Lösungen, sondern auch neue Probleme. Deshalb schlagen wir vor, mögliche Entwicklungen anhand exponierter "soziotechnischer Probleme" zu untersuchen. Dieser Beitrag analysiert aktuelle Studien zur Sektorkopplung und bewertet die Folgen der Konvergenz von Infrastrukturen.

Keywords: complexity, control, socio-technical change, decision making, uncertainty

This is an article distributed under the terms of the Creative Commons Attribution License CCBY 4.0 (https://creativecommons.org/licenses/by/4.0/)

https://doi.org/10.14512/tatup.29.2.17

Submitted: 20.02.2020. Peer reviewed. Accepted: 15. 05.2020

\section{Introduction}

Basic services in modern society - energy supply, transport, heating and cooling - need to be maintained, despite numerous problems such as continuous $\mathrm{CO}_{2}$ emissions, resource scarcity, or dangerous technologies and hazardous waste. Experts call for a holistic transformation of societies' vital infrastructures in order to eliminate, or at least mitigate, these undesirable side effects. To achieve significant reductions in greenhouse gas emissions, the transformation of individual sectors as well as tighter operational coupling and organizational integration of technical and social systems is required (Robinius et al. 2017 a, p. 2 ff.).

In Germany, the idea of sector coupling has become a prominent strategy to meet these objectives. With several emerging technologies enabling sector coupling (including developments in renewable energy sources [RES], heat pumps, combined heat and power [CHP] systems, synthetic fuel production, electric cars, or developments in information and communication technologies), researchers propose different sector coupling pathways that combine research and development activities and energy-related practices. In a broad understanding, the idea of sector coupling refers to the integration of energy systems with the "process of coordinating the operation and planning of energy systems across multiple pathways and/or geographical scales to deliver reliable, cost-effective energy services with minimal impact on the environment" (O'Malley and Kroposki 2017, p. 10).

This vision entails - as we understand it - a process of converging infrastructures that results in the design and implementation of

1. tighter coupling of operations of conservation, conversion, storage, and/or transmission of energy (Beckman 1994, p. 321) in order to impose control of the allocation of systemwide operations (Nightingale et al. 2003), and 
2. tighter organizational and institutional integration to harmonize the interaction of different actors with different purposes, such as design and engineering, supervision, investment, and/ or consumption of services (Franssen and Kroes 2009).

This contribution is concerned with the assessment of possible consequences of converging infrastructures related to sector coupling strategies. We refer to the notion of "socio-technical problems" (Edwards 2004, p. 209) to expose issues that usually receive less attention in engineering or economic modeling, but to which social science research and technology assessment can contribute with complementary perspectives.

Existing research from the fields of science, technology and society studies (STS), large technical systems theory (LTS), systems theory, or transition and innovation research, offers a rich body of literature to (tentatively) extract and differentiate the key issues and reduce them to core socio-technical problems. From a factual point of view, with converging infrastructures, we must assume increasingly complex interactions between technical and social elements, such as physical installations and networks with social organization, and the ensuing quest for maintaining control, e.g., in terms of predictability, security, safety, and efficiency. From a social perspective, the problem of generally shared expectations comes into focus, i. e., institutions where different actors, parties, persons, agents, or stakeholders must find mutual orientation in a converging field, such as energy, transport, and heating/cooling, and where change is enacted upon or by the activities of all parties involved. From a temporal point of view, the problem of coping with uncertainty and risk stresses the need to act in the present, despite the past serving "only" as experience and the future being not yet determined. In this dimension, the consequences of energy transitions are particularly evident, because the resulting structural complex-

Sector coupling will integrate

\section{energy infrastructure in areas that \\ have so far operated side by side.}

ity and institutional change increase non-transparency and challenge the ability to act. All three dimensions represent the socio-technical reality of converging entities and, subsequently, influence each other. The concept of socio-technical problems is laid out in detail in Büscher (2018) and serves as a heuristic to structure possible issues of integration processes (see also the introduction to this TATuP special topic by Christian Büscher, Michael Ornetzeder, and Bert Droste-Franke).

To begin with, we selected recent sector coupling studies for Germany as a data set (acatech et al. 2018; Ausfelder et al. 2017; Bauknecht et al. 2018; Henning and Palzer 2015; Hoffrichter and Beckers 2018; Wietschel et al. 2018; Winter 2018). Almost all of them are studies based on publicly funded projects and claim to provide orientation and advice to policy makers. We therefore assume that these studies have an influence on policy and decision makers in choosing and designing future pathways to integration and coupling of infrastructures. The basic observation is that sector coupling will integrate energy infrastructure (e.g., technical, social, and institutional) in areas that have so far operated largely side by side. In order to explore the consequences of future converging infrastructures, we will direct the following questions to the selected studies and try to identify proposed solutions and remaining issues:

1. With converging infrastructures, we can assume that more and more technical systems and social actors will be intertwined. Consequently, we must ask how the problem of control for secure, reliable, cost-effective, and sustainable operation of the energy system can be solved despite increased socio-technical complexity. What are the technical and organizational means to achieve sector coupling?

2. Change must be enacted in various sectors simultaneously, despite the need for continued reliable operation and secure services. The question arises how and by whom technical and social innovation processes are initiated. Is the public administration, the private sector, or the public at large the driver of sector coupling?

3. Uncertainty must be absorbed in order to maintain the ability to act in the transformation of various sectors. In the face of complicated technologies and complex transformations, social mechanisms must be in effect to enable decision making and action despite increasing non-transparency. Therefore, we need to ask what problems and strategies for coping with uncertainties we can find in our set of studies.

The literature we subsequently analyse offers various pathways to achieving sector coupling, as we will present in the next section. After a brief presentation of these pathways, we will highlight two key findings from the analysis of recent studies: First, in general, many studies emphasize that the idea of converging infrastructures is based on more technical and social diversity, such as the parallel development and existence of different grids and infrastructure networks. Second, the assumptions made in many studies about how sector coupling and integration will come into reality show a strong reliance on politics as initiator, planner, and controller of this process. Along the lines of the questions set out in the introduction, we will discuss the fundamental socio-technical problems behind these premises of sector integration, followed by a short conclusion.

\section{The case of sector coupling}

Sector coupling as a climate protection strategy has gained considerable importance in recent years, since fossil fuels are to be gradually replaced by RES not only in the electricity sector, but 
also in the heating, cooling, and transport sectors (BMUB 2016, p. 3). Sector coupling thus embodies the structural linkage of the various industries (electricity, heating, cooling) and the mobility sector. However, as Wietschel et al. (2018, p. 3) state, there are several definitions of sector coupling, and the available studies take different disciplinary and methodological perspectives: energy system modeling (Ausfelder et al. 2017; Henning and Palzer 2015), political science and decision making (Bauknecht et al. 2018), institutional economics (Hoffrichter and Beckers 2018), social science analyses (Canzler and Knie 2013), and meta-studies (Wietschel et al. 2018; Winter 2018). A rough distinction can be made between a broad and a narrow understanding of sector coupling (Wietschel et al. 2018, p. 3).

Some authors interpret sector coupling narrowly and refer only to the conversion of RES (surplus) electricity into gases or liquids (Power-to-X) as a substitute for fossil fuels (Robinius et al. $2017 \mathrm{a}, 2017 \mathrm{~b}$ ). Others focus on all aspects associated with the coupling of energy-related sectors (e.g., also the use of waste heat) and exclude only those solutions that apply to a single sector, e. g., residential roof-mounted PV systems (Wietschel et al. 2018). Still others additionally emphasize cross-border interdependencies and the potential benefits of international cooperation as crucial aspects of sector coupling (Hoffrichter and Beckers 2018). Bauknecht et al. (2018) look beyond technical aspects and include the flexibilization also of the electricity sector and the reduction of the required expansion of the power grid, e.g., through the use of gas infrastructure.

With regard to the specific technical design of sector coupling paths, the discussed literature basically distinguishes between three options for feeding electricity from RES into the heating, cooling, and transport sectors: (1) direct electrification (e.g., electric cars or heat pumps), (2) indirect electrification divided into two sub-paths a) hydrogen (fuel cells) and b) synthetic fuels, and (3) alternative renewable energies such as biomass, solar thermal or geothermal and waste heat. Due to the limited potential of the third option in terms of energy production, the following analysis will focus on the first two. Figure 1 illustrates elements of sector coupling issues along the socio-technical problem dimensions of control, change, and action (Büscher 2018).

\section{Converging infrastructures - with or despite socio-technical diversity?}

Control problems arise from various endogenous and exogenous changes with regard to the envisioned goal of sector coupling. We need to consider technical and social operations re- sponsible for the production of goods and services as well as exogenous processes such as governance and regulation (Mayntz 2009, p. 124).

Direct electrification as a sector coupling strategy aims to replace current fossil energy use in heating and transport with renewable, low-carbon electricity. The power sector will thus become the main backbone for all energy consuming sectors (acatech et al. 2018; Ausfelder et al. 2017; Henning and Palzer 2015; Wietschel et al. 2018). From a control perspective, several challenges arise. First, end-use devices and corresponding infrastructures in the heat and transport sector need to be replaced by electrical devices. In the heat sector, oil and gas heating systems have to be replaced by electric heat pumps and/or heating networks in combination with CHP plants and increasingly with solar thermal systems, deep geothermal systems, and industrial waste heat recovery. In the transport sector, alternative drive systems such as electric and hybrid vehicles are planned to replace the internal combustion engine. In terms of infrastructure, an expansion of the capacity of vehicle and battery charging infrastructures as well as the development and expansion of the grid are necessary. Meeting the triple challenge of adjusting power supply based on wind and solar energy, expanding grid and charging infrastructure, and replacing end-use devices will be a major task (Henning and Palzer 2015).

A second challenge concerns the interplay between power production, distribution, and consumption. With the expansion of power production from renewables such as wind and solar, a paradigm shift is taking place in the energy sector. In the past, the principle "production follows consumption" meant major control efforts on the production side with control of the utilization of power plant capacity. With fluctuating renewables, the paradigm is reversed to "consumption follows production". The process of balancing electricity supply and network requirements and demand becomes more complicated (D'haese- 
leer et al. 2017). The balancing process is based on flexible load management activities focusing on all three system elements. Adjusted control activities aimed at flexibility will be more decentralized and based on highly digitalized network systems. With sector coupling, the demand side will become even more "unpredictable". While household electricity consumption is relatively easy to forecast based on the daily load profile, charging activities of electric cars, for instance, will be more randomized over day and night. Several studies discuss this challenge with regard to beneficial flexibility options for the system (Ausfelder et al. 2017; Bauknecht et al. 2018; Henning and Palzer 2015).

For indirect electrification via hydrogen and synthetic fuels, the challenge is not only to balance supply and demand, but also to establish global value and supply chains for hydrogen and e-fuel production with connected supply infrastructure for national use. There is consensus that synthetic fuels produced from RES are essential for meeting the Paris Climate Agreement and should be used in transport where no low-carbon alternatives are available (e.g., aviation and shipping) and in energy-intensive industry sectors. Due to structural cost disadvantages for domestic production, supply chains abroad are favored (acatech et al. 2018). Most advocates favor a strategy with technology innovation and development in Germany, followed by an upscaling of Power-to-X technology abroad (e. g., Norway, Morocco, Dubai, or Australia). However, from a control perspective, it is unclear how to steer and manage the establishment of production and supply chains for hydrogen and e-fuels (Hoffrichter and Beckers 2018; Winter 2018).

When combining several sector coupling pathways, an additional control challenge becomes apparent. Different networks and infrastructures are required to implement the different paths (direct and/or indirect electrification). Depending on political and societal priorities the system requires different networks. tablished (see Dekker and van Est in this volume). This raises the question of how operators and supervisors can control parallel grids and networks in terms of service security (vulnerability and resilience), safety (data integrity and privacy), and cost efficiency.

\section{Change strategies for converging infrastructures}

The energy transition, and thus increased sector coupling, is a huge technical and social experiment which has must find a balance between sufficient redundancy and appropriate variance in infrastructure operations (Büscher 2018, p. 23 f.). Given a steadily increasing share of RES, the challenge is no longer the supply of energy, but rather to manage supply and demand accordingly, especially in times of low RES-based energy supply (Bauknecht et al. 2018, p. 40 f.). In this situation, planned (policy) instruments and evolutionary events factor into the process of change. According to current logic, many interventions are conceptualized as a linear cause-effect relationship in which incentives should lead to market and behavioral changes (acatech et al. 2018, p. 4; Wietschel et al. 2018, p.6f.; Winter 2018, p. 16f.). In energy system modeling, this is usually implemented by assuming specific RES shares in energy production, energy efficiency progress, and/or price elasticities of the actors or policy instruments such as regulation or funding programs. However, barriers, e. g., regarding the adoption of climate-friendly technologies, or bounded rationalities, such as a lack of information, are often disregarded.

With converging infrastructures, we must also assume that new actor structures and market opportunities will emerge. The transformation process from today's centralized to decentralized

\section{An expansion of the capacity of vehicle and battery charging infrastructures as well as the development and expansion of the grid are necessary.}

These are electricity networks (both transmission and distribution networks), gas, hydrogen, and heating networks, electricity grids for overhead line trucks as well as rail and road networks and intelligently communicating supply networks (smart grids). Besides these network expansion activities, various types of storage (battery, heat, gas, and hydrogen storage) may be needed (acatech et al. 2018; Schwan et al. 2016). Furthermore, in line with the increasing flexibility of the system, local demand side management (smart meters), consumption and storage partnerships through links to other consumption areas such as mobility, battery electric vehicles as storage (vehicle to grid), and electricity self-consumption will have to be es- supply structures is influenced by many actors and is associated with uncertainties (Bauknecht et al. 2018, p. 36 f.). The likelihood of (sustainable) innovations increases in less regulated, but protected niches (Geels and Schot 2007). The engagement of private individuals (e.g., system-oriented "prosuming" through energy self-consumption by household PV systems), new cooperatives, and new business perspectives (i. e., new business models) even for already established companies fundamentally change the constellation of actors within the system.

In addition, for an (internationally) consistent sector coupling strategy, cross-border interdependencies and international cooperation must be considered (D'haeseleer et al. 2017, p. 67). The 
coordination of national measures to transform European energy systems can be seen as a prerequisite for the development of efficient sector coupling solutions (Hoffrichter and Beckers 2018, p. 48). Political interventions such as, e.g., the internalization of external costs through a $\mathrm{CO}_{2}$ price, an expanded emissions trading system (ETS) or through a $\mathrm{CO}_{2}$-oriented reform of electricity and energy taxes, are crucial for the success of the sector coupling process (acatech et al. 2018, p. 4; Wietschel et al. 2018, p. 6 f.; Winter 2018, p. 16 f.). Several approaches are available, ranging from a centralized governance model (e. g., transnational energy-only market) to a decentralized governance model (Hoffrichter and Beckers 2018, p. 22 f.). In this context, many is-

\section{The energy transition, and thus} increased sector coupling, is a huge technical and social experiment.

sues remain unresolved, such as the structure of adequate longterm governance and the coordination of decision-making processes involving the EU, national, and local levels in the context of sector coupling.

Most studies of sector coupling assume that politics is the main driver for a far-reaching convergence of energy/electricity, transport, heating and cooling. Therefore, action is supposed to be based on political programs that provide incentives for desired transactions (for example via price signals) leading to research and development of technologies and investment in new technologies that promote sector coupling. Uncertainty, then, is a stimulus for innovation, but only if politics is committed to the overall goal of the energy transition in the long term (Canzler and Knie 2013, p. 15). All studies emphasize that trust in long-term, reliable, and transparent political programs is the fundamental mechanism of uncertainty absorption and thus stimulus for risk taking and action by the industry (acatech et al. 2018, p. 53).

On the other hand, the reviewed studies analyze political risks without giving any indication how political decision-makers might cope with uncertainty. A general problem is the lack of acceptance of large scale infrastructure projects such as transmission lines, which particularly hinders the development path of direct or high degree of electrification (Ausfelder et al. 2017, p.59). Specific problems that may arise are:

- failing subsidy allocation and free-rider effects resulting in undesired exploitation (deadweight effects) where companies receive financial resources they would have invested anyway (Ausfelder et al. 2017, p. 141);

- failing incentives where too low a price (a tax or a certificate) might not motivate people to invest in energy efficiency, renewable energies, and technologies for coupling the energy sectors (acatech et al. 2018, p. 59);
- economic inefficiency of technology-specific regulations, which might hinder transparent competition between different technologies in achieving political goals such as reducing $\mathrm{CO}_{2}$ emissions (acatech et al. 2018, p. $55 \mathrm{f}$.);

- migration of businesses due to resistance from energy-intensive industries to higher prices (via taxes or certificates) and possible relocation of production sites if these prices remain a purely national policy and are not applied in the EU and elsewhere (acatech et al. 2018, p. 58; Ausfelder et al. 2017, p. 131).

As for the role of the "prosumer", non-professional users have to take risks in future integrated and smart infrastructures. One aspect is the complexity of smart grids, in which RES technologies and information technologies represent novel possibilities for electricity supply, transport, and heating. Novel control technologies might burden users who normally rely on simplification and routine behavior (Canzler and Knie 2013, p. 95). The other aspect is that the costs of shared infrastructure in communal projects increases the risk for participants and their financial commitments (Canzler and Knie 2013, p. 94).

All in all, we find no evidence that the studies consider uncertainty and risk in the operation of converging infrastructures. After all, the developments in question touch on issues such as centralization vs. decentralization: If more complicated tight couplings are introduced in future infrastructures, the danger of systemic risk might increase (Hellström 2009, p. 327). Failures in one part of the overall complex can lead to a cascade of failures in other parts if sectors (systems) become increasingly coupled. On the other hand, with the emergence of a more decentralized energy system, more redundancies come into effect, which might increase the resilience of the overall complex (Kröger and Nan 2018). The issue of integration vs. disintegration also moves into the focus. US and European policy has for decades supported vertical disintegration along the value chain of energy supply, transmission, and distribution (unbundling) to promote more market-oriented coordination (Coutard 1994). In sector coupling, on the other hand, system planners and supervisors focus on horizontal integration - via the coupling of different infrastructures. This means, for example, that any regulatory attempt must account for the consequences of decision making in a much larger and more complex entity. Planning and risk assessment are thus faced with new problems of responsibility and liability.

\section{Conclusion}

The future of converging infrastructures through sector coupling is a visionary and ambitious project, which may entail a heavy burden of increased complexity and contingency as well as increased uncertainty and the need for risk-taking. In addition, the energy transition is subject to constant technological change and occasional disruptive events, such as accidents (Fukushima) or 
crisis situations (coronavirus pandemic), which may fundamentally change the conditions of planned action programs.

The studies we analyzed describe a coherent set of commonly shared goals, seeing sector coupling as a promising strategy to increase resource and energy efficiency and reduce greenhouse gas emissions. Against this background, the studies focus on laying out a variety of optional sector coupling pathways that are generally considered feasible, efficient, and effective. The main pathways refer to direct or indirect electrification (sometimes a third pathway is added, namely alternative renewable energy
Finally, it remains largely unclear how the overall change process toward sector coupling is initiated and triggered. We have noted an almost complete reliance on politics, which is expected to implement financial incentives or subsidies. Although politics is seen as the central actor in steering the sector coupling process, the interaction between different actors (e. g., business, municipal actors, or civil society, etc.) is not discussed. Very few studies elaborate on bottom-up activities to stimulate sustainable innovations (see Ornetzeder and Sinozic in this volume). Finally, the decision-making process for sector coupling in a multi-level

\title{
Although politics is seen as the central actor
}

\author{
to steering the sector coupling process, interaction between \\ different actors needs to be analyzed more closely.
}

sources). The set of optional pathways includes volumes (of energy sources) and capacities (of transport, distribution, and consumption, respectively), technical needs and future options, feasibility and compatibility, as well as market requirements and macroeconomic efficiency. However, several issues remain open as to how to make this vision a reality.

The conceptualized pathways assume a degree of social behavioral adaptation, with investment and routine braking consumption decisions that are hard to realize. There are lock-in effects (e. g., long investment cycles for certain technologies), trade-offs, and inefficiencies due to structural and individual behavioral decision-making traditions that hinder action and change in sector coupling. The elaborated sector coupling pathways highlight the paradigms of technical feasibility and economic efficiency, underestimating the (assumed) requirements and consequences for consumer action and institutional decision making alike. The techno-economic optimization approach must be complemented by implementation research considering power structures and individual decision making.

Also, innovation and exnovation management and regulation strategies will play a central role in successful sector coupling strategies (David and Gross 2019). There is some discussion about the transition process with a parallelism between the shutdown of old and the opening of new technology pathways (such as the fossil fuel phase-out). However, in particular with regard to the transport sector, efforts to proactively manage defossilization and thereby the "exnovation" of fossil-fuel-based technologies are currently less apparent. With regard to behavioral changes and the diffusion of technologies, the studies mostly assume linear cause-effect relationships (with a focus on $\mathrm{CO}_{2}$ prices through taxation, subsidies, or ETS) - in the hope of achieving desired effects. Socio-technical dynamics in the change process - such as varying acceptance depending on the technological solution or varying degrees of willingness to change behavior in society - are ignored. governance system (interplay of local, federal, national, or even European and global levels) needs to be specified. Among the optional sector coupling pathways, policy makers need to prioritize and decide on the pathways to follow.

\section{Acknowledgement}

We would like to thank our former colleague Chiara lurato who gave us valuable and creative input for the conceptual idea of this paper.

\section{References}

acatech - National Academy of Science and Engineering; Leopoldina - German National Academy of Sciences; Akademieunion - Union of the German Academies of Sciences and Humanities (2018): Coupling the different energy sectors. Options for the next phase of the energy transition. Munich: acatech - National Academy of Science and Engineering; Leopoldina German National Academy of Sciences; Akademieunion - Union of the German Academies of Sciences and Humanities.

Ausfelder, Florian et al. (2017): Sektorkopplung. Untersuchungen und Überlegungen zur Entwicklung eines integrierten Energiesystems. Munich: acatech National Academy of Science and Engineering; Leopoldina - German National Academy of Sciences; Akademieunion - Union of the German Academies of Sciences and Humanities.

Bauknecht, Dierk et al. (2018): Visionen und Pfadentscheidungen der Energiewende. Ein Bericht im Rahmen des Kopernikus-Projekts ENavi. Potsdam: Geschäftsstelle des Kopernikus-Projekts Energiewende-Navigationssystem I ENavi.

Beckman, Svante (1994): On systemic technology. In: Jane Summerton (ed.): Changing large technical systems. Boulder: Westview Press, pp. 311-331. BMUB - Bundesministerium für Umwelt, Naturschutz, Bau und Reaktorsicherheit (2016): Klimaschutzplan 2050. Klimaschutzpolitische Grundsätze und Ziele der Bundesregierung. Berlin: Bundesministerium für Umwelt, Naturschutz, Bau und Reaktorsicherheit.

Büscher, Christian (2018): Framing energy as a sociotechnical problem of control, change, and action. In: Christian Büscher, Jens Schippl and Patrick Sumpf (eds.): Energy as a sociotechnical problem. An interdisciplinary 
perspective on control, change, and action in energy transitions. London: Routledge, pp. 14-38.

Canzler, Weert; Knie, Andreas (2013): Schlaue Netze. Wie die Energie- und Verkehrswende gelingt. Munich: Oekom.

Coutard, Olivier (1994): Economics of grid systems in reconfiguration. Competition in the electricity supply industry. In: Jane Summerton (ed.): Changing large technical systems. Boulder: Westview Press, pp. 163-189.

David, Martin; Gross, Matthias (2019): Futurizing politics and the sustainability of real-world experiments. What role for innovation and exnovation in the German energy transition? In: Sustainability Science 14 (4), pp. 991-1000.

D'haeseleer, William; de Vries, Laurens; Kang, Chongqing; Delarue, Erik (2017): Flexibility challenges for energy markets. Fragmented policies and regulations lead to significant concerns. In: IEEE Power and Energy Magazine 15 (1), pp. 61-71.

Edwards, Paul (2004): Infrastructure and modernity: Force, time, and social organization in the history of socio-technical systems. In: Thomas Misa, Philip Brey and Andrew Feenberg (eds.): Modernity and technology. Cambridge: MIT Press, pp. 185-225.

Franssen, Maarten; Kroes, Peter (2009): Sociotechnical systems. In: Jan Olsen, Stig Pedersen and Vincent Hendricks (eds.): A companion to the philosophy of technology. Chichester: Wiley-Blackwell, pp. 223-226.

Geels, Frank; Schot, Johan (2007): Typology of sociotechnical transition pathways. In: Research Policy 36 (3), pp. 399-417.

Hellström, Tomas (2009): New vistas for technology and risk assessment? The OECD programme on emerging systemic risks and beyond. In: Technology in Society 31, pp. 325-331.

Henning, Hans-Martin; Palzer, Andreas (2015): Was kostet die Energiewende? Wege zur Transformation des deutschen Energiesystems bis 2050. Freiburg: Fraunhofer ISE.

Hoffrichter, Albert; Beckers, Thorsten (2018): Cross-border coordination as a prerequisite for efficient sector coupling in interconnected power systems. Institutional economic considerations on allocating decisionmaking competencies in the European Union. Berlin: Technische Universität Berlin.

Kröger, Wolfgang; Nan, Cen (2018): Power systems in transition. Dealing with complexity. In: Christian Büscher, Jens Schippl and Patrick Sumpf (eds.): Energy as a sociotechnical problem. An interdisciplinary perspective on control, change, and action in energy transitions. London: Routledge, pp. 41-78.

Mayntz, Renate (2009): The changing governance of large technical infrastructure systems. In: Renate Mayntz (ed.): Über Governance. Institutionen und Prozesse politischer Regelung. Frankfurt am Main: Campus Verlag, pp. 121-150.

Nightingale, Paul; Brady, Tim; Davies, Andrew; Hall, Jeremy (2003): Capacity utilization revisited. Software, control and the growth of large technical systems. In: Industrial and Corporate Change 12 (3), pp. 477-517.

O'Malley, Mark; Kroposki, Benjamin (2017): Unlocking flexibility. Energy systems integration. In: IEEE Power and Energy Magazine 15 (1), pp. 10-14

Robinius, Martin et al. (2017 a): Linking the power and transport sectors. Part 1: Modelling a sector coupling scenario for Germany. In: Energies 10 (7), p. 22. DOI: $10.3390 / e n 10070956$.

Robinius, Martin et al. (2017 b): Linking the power and transport sectors. Part 2: Modelling a sector coupling scenario for Germany. In: Energies 10 (7), p. 23. DOI: $10.3390 /$ en10070957.

Schwan, Gesine; Treichel, Katja; Höh, Anne (2016): Sektorkopplung. Von der Stromwende zur Energiewende. Berlin: HUMBOLDT-VIADRINA Governance Platform.

Wietschel, Martin et al. (2018): Sektorkopplung. Definition, Chancen und Herausforderungen. Karlsruhe: Fraunhofer ISI.

Winter, Martin (2018): Effiziente Kopplung der Sektoren Energie und Verkehr. Berlin: Technische Universität Berlin.

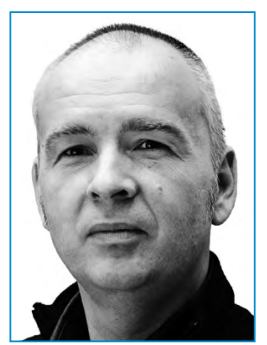

DR. CHRISTIAN BÜSCHER

is since 2006 member of scientific staff at the Institute for Technology Assessment and Systems Analysis (ITAS). His research topics cover the theoretical embedment of technology assessment, social science-based energy research and risk and ecological sociology.
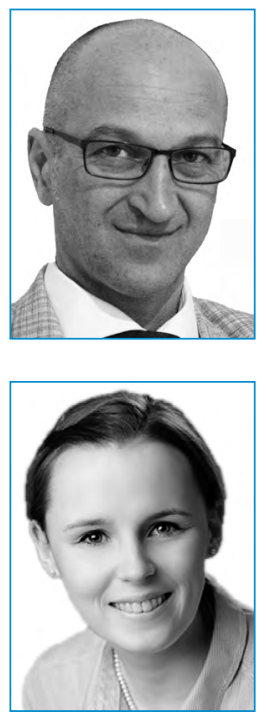

\section{DR. DIRK SCHEER}

works since 2017 as senior researcher at the Institute for Technology Assessment and Systems Analysis (ITAS). His research interests are on socialscience based energy research, technology acceptance research, knowledge transfer and management at the science-policy interface, participation and risk research, and future knowledge.

\section{LISA NABITZ}

joined ITAS in 2017 as member of the scientific staff. Her focus is on social science analyses on the German energy transition (Energiewende), design and evaluation of energy policy instruments, energy efficiency in industry, transitions research, MultiLevel Perspective (MLP), and Technological Innovation System (TIS) research. 